\title{
TRADUCCIÓN: UN RECORRIDO SELECTIVO POR ACERCAMIENTOS CONTEMPORÁNEOS Y SU RELACIÓN CON LA TRADUCCIÓN BÍBLICA
}

\section{Resumen}

El artículo expone las diversas teorías aplicadas a la traducción bíblica, evalúa sus dones y dificultades. Señala que el traductor no debe alinearse con sola una teoría y aplicarla exclusivamente a todo el proceso de traducción, sino que debe buscar utilizar en cada caso los recursos que mejor convengan a un texto en particular. Reconoce el texto bíblico como un producto híbrido, donde confluyen diversas culturas y diversos contextos históricos y sociales, y en el cual la traducción de la Biblia que se ha ofrecido a los pueblos originarios ha producido un cambio cultural que ha profundizado el proceso de hibridación textual y cultural de esos pueblos.

Palabras clave: Traducción bíblica. Pueblos originarios. Biblia y cultura.

\section{Introducción}

Comenzamos citando a Friedrich Schleiermacher: "El que elocuciones se traduzcan de un idioma a otro es un dato que enfrentamos en todos

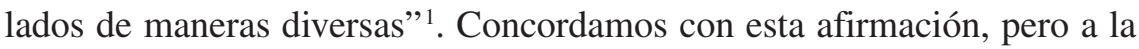
vez sugerimos con insistencia que la traducción se da en todos lados, aun dentro del mismo idioma. Esto lo podemos ver claramente en cómo se habla el español en los diferentes países de Latinoamérica. Palabras del mismo idioma tienen diferentes significados en diferentes países del continente y en diferentes épocas. La razón por la cual comenzamos con la afirmación

1 F. Schleiermacher, “On the Different Methods of Translating”, en L. Venuti (ed), The Translation Studies Reader, London - New York 2004, 49. 
de Schleiermacher es porque en este siglo XXI se cuestiona la práctica de la traducción y hasta se sugiere que la traducción es una tarea imposible de realizar. Sin embargo, al considerar algunos de los acercamientos contemporáneos que se utilizan para traducir, queremos subrayar nuestra hipótesis de que la "traducción" es posible, y de que se lleva a cabo en diferentes lugares, en diferentes niveles y con propósitos diversos. Algunos considerarán que esta postura es un tanto ingenua. No obstante "creemos" que la comunicación es posible y que la traducción es parte integral de esa comunicación.

Desde el principio también queremos compartir una hipótesis de trabajo que nos puede servir como trasfondo a los diferentes acercamientos que se utilizan para la disciplina de la traducción.

Al enfrentarnos con una traducción debemos tener en cuenta el contexto del original, el del texto de destino, y, más importante aún, la distancia entre los dos. Es en esta distancia -en una Babel de desplazamientos lingüísticos, temporales y espaciales- donde ocurre todo: donde se transmiten o se pierden, se renegocian, reexaminan y reinventan textos y culturas ${ }^{2}$.

Nuestro recorrido por los distintos acercamientos debe colocarse dentro de este perder, renegociar, reexaminar y reinventar. Sugerimos entonces que los distintos acercamientos y las distintas teorías de traducción siempre luchan con estos elementos, y en particular con "la distancia" que existe entre ellas. Será importante que mantengamos en mente esta hipótesis al analizar diferentes teorías que se utilizan para hacer la tarea de traducción.

Traductores -hombres y mujeres- que están involucrados en la tarea de traducir siempre están "teorizando". Es muy probable que lo estén haciendo sin darse cuenta, pero la verdad es que siempre están eligiendo y descartando opciones que son diferentes, pero que son igual de valederas. Todo esto se da a partir de algún tipo de teoría. En los últimos cuarenta años aproximadamente se ha reflexionado mucho sobre la teoría y la práctica de la traducción. Como resultado de esta actividad intelectual han surgido varias teorías y acercamientos a la tarea de traducción. Algunas de ellas son más teóricas y filosóficas, y otras son más concretas y prácticas. Asimismo, como hemos dicho más arriba, la práctica de la traducción siempre se ha llevado a cabo con o sin una teoría de la traducción explicitada.

Antes de analizar algunas de las teorías contemporáneas queremos considerar el tema de lo que llamamos "texto sagrado". A pesar de que en estos años muchos han intentado minimizar la diferencia entre lo que lla-

2 S. Waisman, Borges y la traducción, Buenos Aires 2005, 9. 
maremos "texto sagrado" y otros textos, sugerimos que la traducción de un "texto sagrado" conlleva una serie de elementos particulares que no se deben ignorar y que no necesariamente están presentes en la traducción de otros tipos de texto. Consideraremos estos elementos en la medida que vayamos dialogando con las distintas teorías que comienzan a tener una influencia sobre cómo se traduce un texto sagrado. Un asunto un tanto preliminar que queremos mencionar desde el principio es que la mayoría de los que traducen "textos sagrados" generalmente trabajan con una idea a priori que sostiene que existe un original que es estable. Esta presuposición, consciente o inconsciente, será desafiada en este trabajo.

\section{Equivalencia}

El concepto o la idea de equivalencia ha estado presente en la tarea de traducción desde hace mucho tiempo. Podríamos hasta decir que la idea de equivalencia está presente de una manera u otra en las teorías contemporáneas de traducción. A su vez, el concepto de equivalencia ha sido evaluado y explicado de diferentes maneras a través de los años. Quizá una de las sugerencias más recientes es aquella formulada por Eugene Nida, quien lo definió como "equivalencia dinámica". Nida sostiene que una manera de definir la equivalencia dinámica es describirla como "el equivalente natural más cercano al mensaje del texto fuente". Esta definición contiene tres elementos fundamentales: 1) equivalente, que apunta al texto fuente; 2) natural, que apunta hacia el idioma receptor, y 3) más cercano, que une las dos orientaciones a base del grado más alto de aproximación ${ }^{3}$.

Una meta importante de la teoría de equivalencia dinámica es producir el mismo efecto en los lectores u oyentes del texto destino que el texto fuente produjo en los supuestos lectores u oyentes originales. Es decir, se busca que la respuesta o reacción de los receptores al texto traducido sea la misma que la de los receptores originales que vivieron hace más de dos mil años. Esto significa que equivalencia se puede entender como ese concepto que sugiere que hay una relación de igual valor entre el texto fuente y el texto receptor. Por tanto, la traducción que se guía por esta teoría es la que privilegia la equivalencia de respuesta o reacción a la equivalencia de forma.

Pasado cierto tiempo, Nida junto con De Waard sugirieron una variante con respecto al término "equivalencia dinámica" y ofrecieron, en cambio, el término "equivalencia funcional" como una nomenclatura más

3 E. A. NidA, Toward a Science of Translation, Leiden 1964. 
apropiada. Esto se debió a que habían surgido algunos malentendidos y un uso equivocado del término "equivalencia dinámica". Es entonces que la nomenclatura "equivalencia funcional" se contrapuso a lo que se llamaría "equivalencia formal". En este último caso se privilegia el texto fuente y, por ende, la traducción debe intentar preservar la forma original lo más posible. En un sentido, esto se asemeja más a lo que comúnmente se llama una traducción más literal, si bien sabemos que una traducción absolutamente literal es imposible. En cambio, en cuanto a la equivalencia funcional, si bien existe una preocupación por comprender la forma y la cultura del texto fuente, lo que más interesa es cómo los receptores comprenderán el texto traducido ${ }^{4}$. Nida es por demás elocuente cuando afirma que la conformidad de una traducción al idioma y a la cultura receptora es un ingrediente esencial para cualquier traducción estilísticamente aceptable ${ }^{5}$. Todo esto nos indica que, de acuerdo a este acercamiento, "equivalencia" se puede lograr en cualquier nivel lingüístico. Además, también presupone que hay una equivalencia preexistente entre culturas o idiomas antes de que se lleve a cabo una traducción.

En un sentido, Schleiermacher había anticipado esto al argumentar que las traducciones se podían comprender como extranjerizantes o domesticantes. Es verdad que él no utilizó estas palabras precisamente, pero, entre traductores, Schleiermacher es famoso por sugerir este concepto al decir: "O el traductor deja al autor en paz todo cuanto sea posible y mueve al lector hacia él, o deja al lector en paz todo cuanto sea posible y acerca al autor hacia él". Estos dos caminos son tan diferentes el uno del otro que, al traducir, según Schleiermacher, uno tiene que seguir uno u otro de manera estricta. Y cualquier intento de combinarlas ha de producir un resultado poco confiable, ya que se corre el riesgo de que el autor y el lector nunca se encuentren ${ }^{6}$. Una traducción extranjerizante sería una que sigue la estrategia de equivalencia formal a través de la cual la traducción hace el intento serio de seguir las palabras y la forma del texto fuente. Una traducción domesticante sería la que sigue la estrategia de equivalencia funcional, a través de la cual la traducción intenta suscitar en el texto destino el mismo efecto que el texto fuente produjo en los oyentes o lectores originales. Sin duda hay ejemplos extremos de esto, como cuando la metáfora semita "cordero de Dios" se convierte en "la foca de Dios" en la cultura inuit, y

${ }^{4}$ E. A. NidA - J. DE WAARD, From One Language to Another. Functional Equivalence in Bible Translating, Nashville 1986.

5 NidA, Toward a Science.

6 Schleiermacher, "On the Different Methods", 49. 
quizá aún más extremo sería el caso en que esa misma metáfora se traduce como "cerdito de Dios" en Papúa Nueva Guinea. Esto sucede porque en ninguna de estas culturas existe el conocimiento de lo que es un cordero en términos literales ni el concepto en términos figurativos. Desde ya que estos son ejemplos extremos que ofrecemos para demostrar lo peligroso que puede ser utilizar cualquier estrategia de manera extrema. Esto entonces nos lleva a cuestionar la afirmación de Schleiermacher de que no se deben combinar distintos acercamientos o teorías en una misma traducción. Sugerimos que es casi inevitable combinar estas dos estrategias en algunas traducciones, y en especial en la traducción de un "texto sagrado". Sin duda, uno como traductor puede preferir una estrategia sobre la otra, y utilizarla todo cuanto sea posible. A su vez, no nos parece aconsejable el uso de una al punto de excluir de manera absoluta la otra.

Eugene Nida fue un genio en su tiempo, y a la vez un producto de su tiempo. Cuando uno evalúa sus propuestas y teorías, que surgen de su trabajo de campo, siempre debe mantener en mente el contexto histórico en el cual él desarrolló sus sugerencias. No obstante, esto no nos exime de formular algunas críticas y sacar a luz algunos problemas que aparecen al aplicar su teoría de equivalencia funcional de manera excluyente. Esto lo hacemos con total respeto por la persona y la obra de Eugene Nida.

Una pregunta preliminar que podemos articular desde un lugar más contemporáneo es la cuestión de la naturaleza del texto fuente en cualquier ejercicio de traducción. La equivalencia funcional parece darle un lugar prioritario al texto fuente. Se insinúa de manera sutil que el texto fuente es siempre superior al texto receptor. En otras palabras, el texto fuente siempre tiene una posición privilegiada por sobre el texto receptor. Esto conlleva que el texto traducido sea visto como algo de menor calidad o importancia, porque la "verdadera" autoridad yace en el texto fuente. Esto se ve claramente en el ejercicio de traducir un "texto sagrado", ya que existe una especie de respeto santo por el "original", que en general no existe. Sin embargo, en el imaginario del traductor de textos sagrados existe un "original" en algún lugar que tiene toda la autoridad. Por eso nos animamos a sugerir que en realidad no hay textos definitivos, y que, por tanto, lo que tenemos como textos fuente en última instancia son "borradores" o "versiones". Esto nos sugiere que las traducciones no son inferiores a los textos fuente, y de esta manera el proceso de traducción adquiere poder y relevancia como actividad humana. Proponemos entonces que no es necesario $a$ priori considerar que una traducción es inferior a un supuesto "original" o texto fuente. De esta manera desafiamos el concepto de la supremacía del texto fuente en un evento de traducción. 
Otro punto de discusión tiene que ver con la idea o creencia de "la estabilidad del texto fuente". En el modelo de equivalencia existe una especie de presuposición de que el texto fuente es un texto estable. Esto conduce a pensar que el texto fuente es un texto definitivo, y no un borrador o una versión. Las teorías más modernas de traducción cuestionarían esta idea de que el texto fuente es un texto estable. En realidad, uno puede sugerir que tal cosa no existe. Todos los textos son móviles, inestables y no fijos, ya que, en última instancia, son "borradores". A su vez debemos aclarar que tampoco uno debe considerar la traducción de un texto como superior al texto fuente. Si hay algo que podemos decir es que tanto el texto fuente como el texto receptor (traducido) son igual de legítimos y poseen el mismo poder y estatus.

La inestabilidad de los textos se ve claramente en los textos bíblicos, considerados sagrados. La bien desarrollada disciplina conocida como "crítica textual" demuestra una y otra vez esta realidad. A medida que se descubren nuevos y mejores manuscritos del texto fuente se puede sugerir que los textos sagrados nunca fueron estables y definitivos. La cantidad de variantes que aparecen cuando uno compara manuscritos de estos textos sagrados da cuenta de que los textos denominados "originales" o "textos fuente" existieron en un estado constante de fluidez. A esta realidad le podemos agregar la antigua tradición de traducción de estos textos hebreos, griegos y arameos a otros idiomas de la antigüedad. Estas traducciones en sí muestran claramente la inestabilidad de estos textos fuente. Esto también señala que el conocimiento de estas lenguas antiguas no necesariamente garantiza la posibilidad de conocer o traducir un texto definitivo. Es más, no conocer los idiomas originales del texto bíblico sagrado abre el acceso a una variedad de versiones para el lector que puede enriquecer su experiencia de dichos textos.

Otro elemento que debe ser considerado está relacionado con algo que ya mencionamos referente a la estrategia de equivalencia funcional. En este acercamiento encontramos una presuposición que argumenta que hay una equivalencia preexistente entre culturas o idiomas aun antes de que la traducción se lleve a cabo. Dicho de otra manera, la teoría de equivalencia funcional supone que se puede producir un texto estable en idiomas que tienen una capacidad expresiva similar. Esto significa que existe una simetría entre todos los idiomas y, por tanto, que se pueden lograr respuestas iguales en el proceso de traducción. Por el contrario, nosotros proponemos que tal simetría "automática" no existe entre todos los idiomas. Nuestra experiencia en la traducción a idiomas "indígenas" o a lenguas minoritarias que no son occidentales nos enseña que no existe una capacidad expre- 
siva que sea igual entre todos los idiomas, y por tanto no siempre se puede lograr una equivalencia dinámica o funcional. Con esto no estamos diciendo que la comunicación sea imposible, pero, tal como lo afirmó Nida, toda comunicación es parcial.

\section{Teoría de traducción skopos}

Skopos es una palabra griega que en general significa lo siguiente: "propósito", pero también "meta" e "intención". Utilizaremos mayormente el significado "propósito" como la idea principal de esta teoría de traducción ${ }^{7}$. Esta teoría representa un acercamiento que también cuestiona algunos de los supuestos que están entretejidos en el modelo de equivalencia. Pero, a su vez, ciertos elementos de la teoría de equivalencia se encuentran en la teoría de skopos. Aunque esta teoría propone algunos elementos correctivos para la teoría de equivalencia, también bebe de la fuente de equivalencia en distintas etapas.

Para comenzar, queremos destacar que la prioridad de esta teoría está en definir lo mejor posible el "propósito" de la traducción, y en particular establecer el propósito comunicativo de dicha traducción. Sugerimos que lo nuevo expresado y articulado en esta teoría de traducción es el planteo de que el texto receptor puede fungir de manera diferente a la del texto fuente. Esto significa que cualquier texto fuente puede traducirse de diferentes maneras. lo cual redunda en textos receptores que funcionan de maneras distintas a pesar de provenir de un mismo texto fuente. Esta sería la principal diferencia entre esta teoría y la de equivalencia. En skopos o teoría de propósito, la función del texto receptor tiene prioridad por sobre el texto fuente. Ahora bien, esto no significa que en algún punto la función del texto fuente sea igual a la función del texto receptor. Sin duda, en algunos casos pueden llegar a coincidir, siempre y cuando esto esté estipulado desde el principio. Pero esto no es un elemento condicionante para que se lleve a cabo una traducción. Por otro lado, esta teoría genera consecuencias significativas para la metodología que implementar, especialmente desde el principio de dicha traducción.

Una de las cuestiones que esta teoría subraya y privilegia es el rol del cliente. En cuanto a una traducción de la Biblia existen varias posibilida-

7 Dos obras que se deben mencionar para este tema y que fueron publicadas en 1984 son: Grundlegung einer allgemeinen Translationstheorie, de K. REISS - H. VERMEER, y Translatorisches Handeln. Theorie und Methode, de J. Holz-MäntTÄrI. 
des. El cliente puede ser una Sociedad Bíblica nacional, o una Iglesia local, o una denominación internacional, o una agencia bíblica, o un departamento de cultura de algún grupo étnico minoritario, o todos a la vez. El rol del cliente es crítico, porque define, determina y elige qué tipo de traducción será contratada. Junto con esto, el cliente debe definir para el traductor o equipo de traducción cuál será la función del texto destino. En algunos casos, el cliente puede optar por mantener lo que se percibe que es la función del texto fuente, siempre y cuando uno considere que eso es posible. Pero, como hemos establecido que un texto cualquiera puede traducirse de diferentes maneras, también es posible que el cliente solicite que la función del texto receptor sea diferente a la función que se percibe que cumple el texto fuente. Y entonces el asunto de la comunicación adquiere mayor relevancia. A fin de cuentas, el cliente debe definir claramente para los traductores qué es lo que se debe comunicar y cómo hacerlo. A riesgo de caer en la redundancia repetimos: el criterio último de esta teoría es "qué propósito" se busca lograr.

El proceso a través del cual el cliente le expresa sus deseos a los traductores se ha denominado de diferentes maneras: "una hoja de ruta", "comisión", "descripción de trabajo" o simplemente "instrucciones del cliente". Este es un elemento crítico de esta teoría, ya que es el cliente el que define el propósito de la traducción que se hará. Por más que el experto sea el traductor, él deberá someter su competencia a los deseos y metas del cliente.

Este aspecto de la teoría skopos ha llegado a ser algo muy importante y fundamental para la traducción bíblica moderna, y en particular para los proyectos de traducción de la Biblia de las Sociedades Bíblicas Unidas. En dicha organización se ha adoptado la política que para cada proyecto de traducción de la Biblia que se inicia se pide que antes de comenzar el trabajo en sí, tanto los que coordinan el proyecto como los traductores preparen con mucho cuidado una "hoja de ruta" que explique bien cuál es el propósito de la traducción, y de esta manera todos los involucrados, ya sean una Iglesia, la Sociedad Bíblica local y otros que puedan tener un interés en el producto final estén bien enterados.

Es así que, por ejemplo, el propósito y las características de la audiencia que recibirá la traducción son elementos indispensables para la "hoja de ruta". Y para confeccionar dicho documento se necesita responder a varias preguntas, tales como: ¿cómo se diferencia esta nueva traducción de otras que ya existen en la comunidad?, ¿cuáles son las expectativas que se deben cumplir?, ¿será en verdad una nueva traducción o un revisión?, ¿se dirigirá a un sector en particular de la sociedad (gente de Iglesia, juventud, cierto nivel de educación) o no?, ¿de qué manera afectará todo lo anterior al enfoque de la traducción? Cada uno de estos elementos es consi- 
derado de suma importancia y, por ende, deben estar establecidos desde un principio, antes de que se traduzca una sola palabra.

A modo de ilustración presentaremos un ejemplo de una "hoja de ruta". Esto no presupone que sea la única manera de hacerlo, pero sí ilustra cómo se puede hacer algo que realmente ayuda. Sin ser algo absoluto ni perfecto, lo ofrecemos como un método que puede ayudar mucho cuando uno comienza una nueva traducción de la Biblia.

\section{Traducción de la Biblia Georgiana Estándar}

\section{Principios}

1. Meta: traducción para el uso general en la Iglesia y en la sociedad dirigida a un público con cierta preparación académica.

2. Texto base que se utilizará: Biblia Hebraica para el Antiguo Testamento, $4^{\text {a }}$ edición del Nuevo Testamento Griego de UBS para el Nuevo Testamento, la LXX para los deuterocanónicos.

3. Traducciones modelo: Texto Patriarcal 1989, texto de IBT/UBS 2001, traducciones georgianas antiguas.

4. Tipo de traducción:

a. En general se seguirá la teoría de equivalencia formal.

b. Idiomática, dentro de lo posible. Georgiano literario.

c. Estilo natural (se deben evitar los literalismos hebreos y griegos si no coinciden con el georgiano natural).

d. Consistencia con la terminología clave, nombres, etc (diferente a las traducciones existentes en georgiano).

e. Evitar frases o palabras arcaicas.

f. Representar o preservar de manera fiel el contexto cultural e histórico original. Datos históricos se deben expresar sin ninguna distorsión. Hacer el intento de transmitir la intención original de los autores.

5. En cuanto a la exégesis, se consultarán los Translation Handbooksi publicados por UBS.

6. Se utilizarán notas a pie de página.

a. Para explicar nombres propios cuando se haga referencia al significado de palabras hebreas o griegas.

b. Cuando el significado de las palabras en hebreo no sea claro.

c. Cuando existan variantes textuales importantes (de versiones antiguas o de manuscritos).

d. Para explicar ideas u objetos desconocidos. 
7. Otras ayudas para lectores

a. Referencias cruzadas.

b. Glosario.

c. Introducciones a los libros de la Biblia.

d. Índice de nombres.

8. Dos ediciones: una con los libros deuterocanónicos y otra sin ellos.

\section{Procedimientos}

- Se debe elegir a los miembros del equipo que traducirán el texto.

- Se debe elegir un coordinador para el proyecto de traducción.

- Se debe asignar un consultor de traducciones de UBS.

\section{Etapas}

1. Primer borrador redactado en ParaTExt ${ }^{8}$ por uno de los miembros del equipo, basado en la asignación de un documento (preguntas, cuestiones para discutir se colocarán en las notas de ParaTExt).

2. Revisión del documento por otros miembros del equipo de manera individual (las sugerencias para mejorar la traducción se colocarán en las notas de ParaTExt).

3. El traductor que redactó el primer borrador evalúa los comentarios de los otros miembros del equipo.

4. Discusión y diálogo entre los miembros del equipo sobre temas no resueltos.

5. El coordinador del proyecto revisa el texto para discernir su consistencia en cuanto a forma y contenido utilizando las herramientas de ParaTExt.

6. El consultor de traducciones revisa el texto, concentrándose en los textos más difíciles y que presentan desafíos para la traducción.

7. Preparación del texto para tipografía.

Este proceso está revestido de varias virtudes dignas de mencionar. Sin duda, el saber el propósito de la traducción de antemano ayuda al traductor a desarrollar una estrategia adecuada para lograr dicho objetivo y cuáles serán los pasos a seguir en el proceso de hacer la traducción. El traductor no

8 ParaTExt es un programa de computación muy potente que ha sido desarrollado por Sociedades Bíblicas Unidas y el Instituto Lingüístico de Verano para hacer traducciones de la Biblia. 
tiene que adivinar cuáles son las expectativas o necesidades de la audiencia receptora. En un sentido, entonces, uno puede decir que el traductor está condicionado y hasta "gobernado" por el propósito final de la traducción. Otra virtud que podemos destacar es que el traductor, al ser gobernado por el propósito de la traducción, puede tener la libertad de utilizar más de una metodología en el proceso de traducción, especialmente cuando se confronta con diferentes géneros literarios. El traductor no se convierte en esclavo ni de la equivalencia funcional ni de un acercamiento más literal y formal, ni de cualquier otro acercamiento que puede ser útil. Esto significa que el proceso puede ser mucho más transdisciplinario y, en consecuencia, mucho más rico.

A su vez, esta teoría del skopos tiene sus costados débiles y se le puede cuestionar y criticar algunos aspectos. El literato británico Peter Newmark ha afirmado que el traductor tiene la capacidad de traducir "palabras", pero no funciones ${ }^{9}$. Esto significa que uno debería matizar el énfasis exclusivo y excluyente del propósito o función de la traducción enarbolada por la teoría del skopos. Esto es particularmente importante cuando uno traduce un texto de la antigüedad para el cual no podemos saber con seguridad cuál fue su propósito original. Sin duda, establecer cuál es la función del texto receptor es importante, pero no necesariamente debe ser excluyente.

Otra cuestión a considerar dentro de este acercamiento es que, en última instancia, el texto fuente tiene sus propósitos, y de alguna manera hay que intentar descubrirlos y darles su lugar correspondiente en el proceso de traducción. A pesar de darle mucho peso a la función de la traducción, un elemento corrector se puede dar al mantener en tensión la realidad del propósito o función del texto fuente, en tanto y en cuanto se pueda discernir con cierta confianza el del texto receptor.

Tomando en cuenta estos cuestionamientos de la teoría skopos, igual podemos resaltar las contribuciones importantes que ha ofrecido esta teoría a la actividad de traducción al quitarle la hegemonía al texto fuente y darle un lugar más adecuado y significativo al texto destino.

\section{Traducción como reescritura ${ }^{10}$}

Traducir significa adoptar ciertas estrategias que de tanto en tanto son diferentes. Esta realidad llevó a André Lefevere a sugerir que traducir

9 P. Newmark, A Textbook of Translation, New York 1988.

10 La fuente de esta sección es una conferencia ofrecida por el Dr. Stefano Arduini en mayo de 2013. El Dr. Arduini es profesor de lingüística en la Universidad de Urbino, Italia. Utilizado con permiso. 
es manipular y reescribir ${ }^{11}$. Según esta perspectiva, traducir es manipular y reescribir, porque traducir tiene mucho en común con otros tipos de interpretación y producción textual, tales como la historiografía, la crítica literaria y el editar. Todas estas actividades tienen como meta la construcción de una imagen del texto, del autor o de toda una cultura literaria y proyectarla en un medio ambiente diferente. La historia de la traducción, y en particular la de la traducción bíblica, es precisamente la historia de la comunidad en relación con otros. En este sentido, el reescribir es repensar un texto en relación con sus propias coordenadas culturales.

En relación con esto es por demás interesante analizar cómo se ha ido desarrollando la percepción de la propiedad literaria, y además la noción de la fidelidad en la traducción. Esta última noción se ha ido modificando a lo largo de la historia, en el sentido de que lo que en un momento era considerado "fiel", en otra época es considerado "infiel". Otro concepto importante a tener en cuenta en esto es el del "patrocinio". Por eso queremos decir que individuos, grupos e instituciones ejercen una influencia importante y hasta animan y censuran el reescribir en la esfera literaria. Esto nos sirve de advertencia para que entendamos que la traducción nunca es una tarea inocente, y además exhibe una dependencia significativa del contexto social y político en el cual se lleva a cabo.

La traducción entonces es reescribir un texto original. Cada vez que se reescribe se lo hace con cierta ideología y poética, y como tal manipula la literatura para que funcione de tal o cual manera. El reescribir es manipular al servicio del poder, y su aspecto positivo puede ayudar a la evolución de la literatura y de la sociedad ${ }^{12}$.

Un aspecto de esta teoría es la de comparar un texto escrito con un discurso oral. Por ejemplo, es muy difícil discernir la fuente precisa de un discurso oral. Es decir, durante una conversación, las oraciones está interconectadas, pero lo que se dice tiene una relación con una cantidad heterogénea de signos y estímulos. Por lo tanto sería muy difícil establecer de dónde vienen esas oraciones.

En cambio, el traductor de un texto tiene más posibilidades de descubrir la fuente de una traducción, ya que siempre podrá apuntar a un pasaje en una página. Pero si le preguntáramos de dónde viene toda la traducción de un texto, la respuesta sería más compleja. Pensemos en una editorial que encarga o contrata una traducción de una novela rusa. La nueva novela

11 A. Lefevere, Translation, Rewriting and the Manipulation of Literary Frame, London - New York 1992, XI.

$12 \mathrm{lb}$. 
escrita por el traductor claramente se originó en la novela rusa. No obstante, se sugiere que la novela original no tiene todo lo que se necesita para producir una traducción, ni tampoco se puede traducir todo lo que tiene el texto original.

Durante el proceso de reescribir, el traductor indefectiblemente hará un mal uso de partes o funciones del texto en ruso. Deberá utilizar su conocimiento global, su conocimiento de las obras del mismo autor, del género literario del texto, de literatura rusa, de objetos culturales descriptos en la obra, etc. Un texto nuevo desperdiciará algunos signos y agregará nuevos. Esto es particularmente cierto para traducciones de la Biblia que precisan un conocimiento de varias culturas antiguas para todo el proceso de traducción.

Otro elemento muy importante que ha surgido en los últimos años es lo que se llama la traducción intersemiótica. Ya las traducciones no se limitan a textos escritos, sino a todo tipo de medios de comunicación. Un ejemplo que se distancia mucho de una traducción de una novela es la "palabra electrónica", que ya no tiene la estabilidad de la palabra impresa. Textos electrónicos pueden cambiar constantemente; no son el resultado inmediato del autor, y así como se puede diseminar, así también puede desaparecer rápidamente.

Estas consideraciones requieren que elaboremos una definición de un concepto nuevo de lo que es un texto, ya no como una entidad limitada encerrada dentro de límites objetivos, sino como un nodo de un espacio ilimitado. Esto lleva a que el texto fuente ya no sea considerado un dato necesario preexistente. La traducción en sí es la que define un conjunto de signos que le servirá de base, y entonces, en un sentido, el texto original es el producto de la traducción.

\section{Traducción cultural}

Comenzamos afirmando algo que para muchos es una obviedad, pero que igual vale la pena recalcarlo: el significado no se mantiene sin alteraciones cuando viaja de una cultura a otra. Además es necesario mencionar dos asuntos desde el principio. En primer lugar es necesario admitir que las culturas no son estables. Cuando tomamos en cuenta traducciones y culturas, trabajamos con el concepto de que las culturas son bastante inestables por causa de varias razones. En segundo lugar, sugerimos que las traducciones tienen la capacidad de modificar o cambiar culturas. Esto no es un fenómeno nuevo que haya aparecido como resultado de la globa- 
lización, aunque sin duda esta tiene una influencia sobre el proceso de traducción. El fenómeno es muy antiguo y se ha dado desde que el ser humano comenzó a realizar traducciones.

Homi Bhabha ${ }^{13}$, un especialista en teoría cultural de la India, ha afirmado con mucha razón que los símbolos de cualquier cultura no son estables y que además se reformulan, se reinterpretan y se traducen de manera constante. Las culturas se redefinen constantemente, y en un sentido se traducen también. Es verdad que podemos sugerir que algunas culturas, como la griega, intentaron ser más homogéneas y separarse de todo el contexto asiático. Pero ni aun los griegos pueden ostentar un sentido de pureza cultural, porque ellos también tienen influencias de otras naciones y de otras costumbres sociales. Stefano Arduini, citado anteriormente, en la misma cátedra sostiene que las culturas no tienen un núcleo estable, y esto hace que sea imposible rescatar sus valores originales y auténticos. Muy por el contrario, las culturas son representaciones inestables que cuestionan relaciones antagónicas que siempre están transformándose. Por ende, no nos confrontamos con entidades definidas, sino con fronteras y sistemas que están en constante transformación y cambio.

Esta realidad dio pie a la idea de la hibridación de culturas ${ }^{14}$. Debemos advertir que el hecho de que uno hable de una cultura híbrida no significa que en algún momento en su historia haya sido una cultura "pura" y original. Muy por el contrario, hablar de hibridación respecto a culturas es sostener que las culturas son el resultado de negociaciones constantes entre culturas, de una interacción entre identidades étnicas donde significados culturales se negocian constantemente. Las culturas, entonces, no son entidades aisladas y cerradas, sino que siempre están sujetas a influencias del afuera.

La inestabilidad de culturas, al igual que la realidad de la hibridación, sin duda tiene una relación con el traductor. Es el traductor que está parado en la brecha o en el espacio "entre" los idiomas. El traductor conoce los dos idiomas, y es entonces obligación que conozca dos culturas. Por lo tanto, es claro que la traducción tiene un efecto sobre la otra cultura al abrirla y exponerla. En otras palabras, la traducción tiene la posibilidad de crear hibridación. La traducción se lleva a cabo bajo condiciones culturales heterogéneas. Esto ha sido analizado por la conocida escuela de Tel Aviv, representada por I. Even-Zohar y G. Toury dentro del marco teórico deno-

13 H. K. BABHA, The Location of Culture, London - New York 1994.

14 N. García Canclini, Culturas híbridas. Estrategias para entrar y salir de la modernidad, Buenos Aires 2001. 
minado "Teoría polysistema" 15 . El concepto de polysistema es un intento de definir todas las actividades que se consideran literarias dentro de una cultura.

Cuando uno se confronta con un texto sagrado que fue redactado a través de siglos en el mundo del Cercano Oriente antiguo, se encuentra con hibridación constantemente. Los textos han viajado geográfica, temporal, lingüística y culturalmente. Esta realidad se vuelve aún más significativa cuando uno traduce este texto "híbrido", o quizá sea mejor hablar de traducir una "cultura híbrida" a idiomas no occidentales en los cuales el vocabulario, la cosmovisión y los valores culturales son tan diferentes. A raíz de diversos análisis y descripciones que se han llevado a cabo descubrimos que introducir el texto bíblico dentro de una cultura que hasta ese momento no se había confrontado con un texto escrito o con un texto teológico semita, esta inserción del texto bíblico ha modificado e influido en las culturas indígenas en las Américas, en África y en Asia. Es más que evidente que la inserción de un texto literario sagrado dentro de otra cultura puede, en última instancia, afectar la jerarquía de valores, las creencias y la comprensión de símbolos y hasta de las tradiciones milenarias. Es decir, la experiencia nos demuestra claramente que lo que la teoría de traducción cultural intenta articular se ve corroborado en la práctica. Hasta qué punto esto se puede considerar como algo positivo o negativo es una cuestión que debatir. Lo que no se puede negar es que la traducción del texto sagrado siempre ha producido un cambio cultural y siempre lo hará. Esta realidad seguirá profundizando y extendiendo el proceso de hibridación textual y cultural.

\section{Reflexiones finales}

El espacio asignado no nos permite indagar en otras teorías y subteorías que se aplican al proceso de traducción. Existen muchas otras teorías que se podrían presentar y analizar, y hay una bibliografía muy extensa que se puede consultar. Sin embargo, al reflexionar sobre las diferentes teorías o paradigmas que continuamente se ofrecen en el campo de los estudios de traducción, y en el campo de la traducción bíblica, estamos cada vez más convencidos de que no debemos permitir que nos capture una sola de ellas. Es nuestra conclusión que uno, como traductor, no debe alinearse con sola una teoría y aplicarla exclusiva y hasta ciegamente a todo el proceso de (1990).

15 I. Even-Zohar, “Polysystem Studies”, número monográfico de Poetics Today 11 
traducción. Esto es realmente aún más cierto para la traducción bíblica. Con esto queremos afirmar que el problema que tienen la mayoría de las traducciones de la Biblia es que, al tratar de aplicar una sola teoría de traducción, se reduce el nivel de comunicación y se achata la profunda riqueza que es inherente al texto sagrado. Los diferentes contextos históricos, culturales, lingüísticos y literarios presentes en el texto bíblico atentan contra todo intento de hacer que todo suene igual y de hacer que todo diga lo mismo. Recomendamos que es importante nutrirse y beber de las muchas contribuciones que se han articulado en la disciplina de teorías de traducción y así poder producir traducciones que no escondan ni minimicen la riqueza presente en el texto sagrado.

ESTEBAN Voth Sociedades Bíblicas Unidas 